\title{
Perovskite solar cells with Cul inorganic hole conductor
}

\author{
Kenta Takahashi ${ }^{1}$ and Yoshikazu Suzuki ${ }^{1,2 *}$ \\ ${ }^{1}$ Graduate School of Pure and Applied Sciences, University of Tsukuba, Ibaraki 305-8573, \\ Japan \\ ${ }^{2}$ Faculty of Pure and Applied Sciences, University of Tsukuba, Ibaraki 305-8573, Japan \\ *E-mail: suzuki@ims.tsukuba.ac.jp
}

\begin{abstract}
An organic material, 2,2' '7,7'-tetrakis(N,N-di-p-methoxyphenylamine)9,9'-spirobifluorene (spiro-OMeTAD), is generally used as a hole conductor of perovskite solar cells (PSCs), but spiro-OMeTAD is much more expensive than other materials used in PSCs. In this study, we have prepared PSCs with a cost-effective CuI hole transport layer by spin coating. The merit of using spin coating for $\mathrm{CuI}$ is good compatibility with other steps, such as spin coating of a $\mathrm{TiO}_{2}$ electron transport layer and a perovskite active layer. The CuI-based PSC recorded power conversion efficiencies of $\eta=2.22 \%$ (max) on the day of production and $\eta=6.52 \%$ (max) after the 20 days of production. Moreover, the CuI-based PSC had a smaller hysteresis than the spiro-based PSC, suggesting that $\mathrm{CuI}$ is a highly promising alternative hole conductor for PSCs.
\end{abstract}

\section{Introduction}

Perovskite solar cells (PSCs) were first reported by Kojima et al. with a power conversion efficiency (PCE) of 3.81\% in 2009. ${ }^{1)}$ Recently, the PCE of PSCs has been much improved to $22.1 \%,{ }^{2)}$ and thus PSCs are focused all over the world. Figure 1(a) shows a conventional structure of PSCs. PSCs are commonly composed of a transparent conductive oxide glass, an electron transport layer (ETL) made from compact and mesoporous oxide films $\left(\mathrm{TiO}_{2}\right.$ or $\mathrm{ZnO})$, a perovskite active layer $\left(\mathrm{ABX}{ }_{3}, \mathrm{~A}=\mathrm{CH}_{3} \mathrm{NH}_{3}, \mathrm{~B}=\mathrm{Pb}\right.$ or $\mathrm{Sn}, \mathrm{X}=\mathrm{I}, \mathrm{Cl}$, or $\left.\mathrm{Br}\right)$, a hole transport layer (HTL), and a metallic electrode (Au, Ag, or Al). Among these layers, we focused on the HTL. In general, an organic material, 2,2',7,7'-tetrakis(N,N-di-pmethoxyphenylamine)9,9'-spirobifluorene (spiro-OMeTAD), is used as a hole conductor, 
and the solar cells using spiro-OMeTAD demonstrate high photovoltaic performances. ${ }^{3-5)}$ However, spiro-OMeTAD is very expensive, i.e., over 10 times more expensive (per mass) than the other materials used in PSCs.

As an alternative hole conductor in PSCs, several organic and inorganic materials, such as poly(triarylamine) (PTAA), ${ }^{6)} \quad$ poly(3-hexylthiophene) $\quad(\mathrm{P} 3 \mathrm{HT}),{ }^{7)} \quad \operatorname{poly[}(9,9-$ dioctylfluorenyl-2,7-diyl)-co-(4,4'-(N-(4-sec-butylphenyl)diphenylamine)] (TFB), ${ }^{8)}$ CuSCN, ${ }^{9-12)} \mathrm{NiO},{ }^{13-15)} \mathrm{CuO}-\mathrm{Cu}_{2} \mathrm{O}^{16-18)}$ and $\mathrm{CuI},{ }^{19-21)}$ have been tested. Among these candidates, $\mathrm{CuI}$ is focused in this study by following features:

(1) low cost $(\sim 1 / 500$ of spiro-OMeTAD),

(2) conduction band position similar to the HOMO level of spiro-OMeTAD ${ }^{22,23)}$ (Fig. 1(b)),

(3) much higher hole mobility (CuI: $0.5-2 \mathrm{~cm}^{2} \mathrm{~V}^{-1} \mathrm{~s}^{-1},{ }^{24)}$ spiro-OMeTAD: $\sim 2 \times 10^{-4} \mathrm{~cm}^{2} \mathrm{~V}^{-1} \mathrm{~s}$ $125,26)$,

(4) thin film deposition at low temperatures (near room temperature), ${ }^{24,27)}$ and

(5) p-type semiconductor (zinc blend structure) with a wide bandgap of $\sim 3.1 \mathrm{eV}$ below $350{ }^{\circ} \mathrm{C}^{28)}$

Christians et al. ${ }^{19)}$ reported the preparation of a CuI HTL by automated drop casting (modified doctor blade method), which resulted in a power conversion efficiency (PCE) of $6.0 \%$ in 2014. Sepalage et al. ${ }^{20}$ also reported the preparation of the CuI HTL by a manual doctor blade method with a PCE of 7.5\% in 2015. Huangfu et al. ${ }^{21)}$ prepared a CuI thick film HTL by spraying with a PCE of 5.8\% in 2015. Recently, Hossain et al. ${ }^{29)}$ have evaluated the optimum thicknesses of several HTLs by a computation method, and pointed out that $~ 200$ $\mathrm{nm}$ is the optimum thickness of the CuI HTL.

To control the film thickness of CuI, spin coating will be easy and effective. Thus, in this study, we have prepared the CuI HTL by spin coating. Another merit of using spin coating for $\mathrm{CuI}$ is good compatibility with other steps, such as spin coating of a $\mathrm{TiO}_{2} \mathrm{ETL}$ and a perovskite active layer. Furthermore, the aging effect (up to 40 days) was evaluated.

\section{Experimental methods}

\subsection{Cell preparation}

Etched ITO glass (Geomatic, type 0052, $10 \Omega /$ sq.) was rinsed with distilled water and then with ethanol for $5 \mathrm{~min}$. A $\mathrm{TiO}_{2}$ compact layer was prepared on the ITO glass by spin coating $0.15 \mathrm{M}$ titanium diisopropoxide bis(acetylacetonate) (75\% in isopropanol, Sigma-Aldrich) solution in 1-butanol at $2000 \mathrm{rpm}$ for $20 \mathrm{~s}$ and annealed at $125^{\circ} \mathrm{C}$ for $5 \mathrm{~min}$. Then, this process 
was repeated twice with $0.3 \mathrm{M}$ diisopropoxide bis(acetylacetonate) (75\% in isopropanol) solution. The substrate was annealed at $500^{\circ} \mathrm{C}$ for $15 \mathrm{~min}$ in air.

A commercial $\mathrm{TiO}_{2}$ paste (Dyesol, 18NR-T) was diluted 5 times with ethanol. $\mathrm{A} \mathrm{TiO}_{2}$ mesoporous layer was prepared on the $\mathrm{TiO}_{2}$ compact layer by spin coating the diluted $\mathrm{TiO}_{2}$ paste at $4000 \mathrm{rpm}$ for $25 \mathrm{~s}$ and annealed at $500^{\circ} \mathrm{C}$ for $30 \mathrm{~min}$ in air. From our preliminary test, 1-time $\mathrm{TiO}_{2}$ mesoporous layer coating was suitable for spiro-based PSCs, and 3-time $\mathrm{TiO}_{2}$ mesoporous layer coatings were suitable for CuI-based PSCs. For each of the 3-time $\mathrm{TiO}_{2}$ mesoporous layer coating, the annealing time was $10 \mathrm{~min}$; thus, the total annealing time was $30 \mathrm{~min}$. Then, each substrate was immersed in $40 \mathrm{mM} \mathrm{TiCl}_{4}$ solution in distilled water at $70^{\circ} \mathrm{C}$ for $30 \mathrm{~min}$, rinsed with ethanol, and annealed at $500^{\circ} \mathrm{C}$ for $45 \mathrm{~min}$ in air.

A perovskite $\left(\mathrm{CH}_{3} \mathrm{NH}_{3} \mathrm{PbI}_{3}\right)$ active layer was prepared by a two-step method in air under 35\% humidity. $\mathrm{PbI}_{2}$ (>98.0\%, Tokyo Chemical Industry) was dissolved in N,Ndimethylformamide (DMF; 99.5\%, Nacalai Tesque). $\mathrm{PbI}_{2}$ solution (1 M) was spin- coated on the $\mathrm{TiO}_{2}$ mesoporous layer at $3000 \mathrm{rpm}$ for $20 \mathrm{~s}$ and annealed at $80^{\circ} \mathrm{C}$ for $10 \mathrm{~min}$ on a hot plate in air. Then, the substrate was immersed in $10 \mathrm{mg} / \mathrm{mL} \mathrm{CH}_{3} \mathrm{NH}_{3} \mathrm{I}$ solution $(98 \%$, Wako Pure Chemical Industry) in 2-propanol (99.5\%, Nacalai Tesque) for 40 s, rinsed in 2propanol and annealed at $80^{\circ} \mathrm{C}$ for $10 \mathrm{~min}$ in air.

As for the HTL, both spiro-OMeTAD (as a control) and CuI were prepared. A spiroOMeTAD HTL was prepared by spin coating (at 4000 rpm for 35 s) spiro-OMeTAD solution ( $\sim 57 \mathrm{mM}$ ) consisting of $73 \mathrm{mg}$ of spiro-OMeTAD (99\%, Sigma-Aldrich), $28.8 \mu \mathrm{L}$ of 4-tertbutylpyridine (TBP; 96.0\%, Sigma-Aldrich), and $17 \mu \mathrm{L}$ of $520 \mathrm{mg} / \mathrm{mL}$ lithium bis(trifluoromethylsulfonyl)imide salt solution (98.0\%, Tokyo Chemical Industry) in acetonitrile (99.5\%, Wako Pure Chemical Industry) in $1 \mathrm{~mL}$ of chlorobenzene (99\%, Nakalai Tesque). The CuI HTL was prepared by spin coating (at $2000 \mathrm{rpm}$ for $35 \mathrm{~s}$ ) CuI solution (0.1 M); CuI powder ( $\geqq 99.5 \%$, Sigma-Aldrich) was dissolved in a chlorobenzene/acetonitrile/4tert-butylpyridine solution at 40:20:1 (in volume ratio). Finally, a gold electrode was deposited by thermal evaporation on top of each device under a pressure of $\sim 1.0 \times 10^{-5}$ Torr.

\subsection{Cell evaluation}

The starting CuI powder, CuI film directly deposited on ITO (by dropping), and prepared solar cells were analyzed by X-ray diffraction (XRD; Rigaku Multiflex, $\mathrm{CuK}_{\alpha}, 40 \mathrm{kV}$ and $40 \mathrm{~mA})$. Current density-voltage $(J-V)$ characteristics were measured with a solar simulator (San-ei Electric XES-40S1), calibrated to AM 1.5, $100 \mathrm{~mW} / \mathrm{cm}^{2}$ with a standard silicon 
photodiode (Bunkokeiki BS-520BK). The active area was $0.087 \mathrm{~cm}^{2}$ with a black mask. The voltage step and delay time were $20 \mathrm{mV}$ and $50 \mathrm{~ms}$, respectively. Three spiro-based and ten CuI-based PSCs were prepared. Photovoltaic performance was measured at 2 points in each cell, and therefore, 6 and 20 data sets were obtained for spiro-based and CuI- based PSCs, respectively. In this paper, the average and the maximum performances of these cells were discussed. The CuI powder and the surfaces of the perovskite active layer and CuI HTL were observed by scanning electron microscopy (SEM; Hitachi High-Technologies SU-70 and JEOL JSM-5600LV).

\section{Results and discussion}

\subsection{Phase analysis}

Figure 2(a) shows XRD patterns of CuI powder and a CuI 'thick' film deposited by dropping $\mathrm{CuI}$ solution on the ITO glass. The XRD pattern of the CuI thick film contained a 111 strong reflection as reported by Cai et al. ${ }^{30)}$ This result confirms that a CuI 'thin' film can be formed by spreading droplets via spin coating. Figure 2(b) shows XRD patterns of the spiro-based and CuI-based PSCs. $\mathrm{CH}_{3} \mathrm{NH}_{3} \mathrm{PbI}_{3}$ peaks were clearly observed for both cells, with some unreacted (or decomposed) $\mathrm{PbI}_{2}$ peaks, as frequently reported for the 2-step method in the literature. Throughout the XRD study, CuI spin coating did not significantly damage the perovskite layer.

\section{$3.2 \mathrm{~J}-\mathrm{V}$ characteristics}

Figure 3 shows $J-V$ curves of the prepared cells: (a) spiro-based PSC (0 day), (b) CuI-based PSC (0 day), (c) spiro-based PSC (after 21 days) and (d) CuI-based PSC (after 20 days). The $J-V$ curves showing the highest performance are plotted in each figure. Inset values are for the best performance: (a), (c), and (d) are for the back scan, and (b) is for the forward scan. Figures 3(a) and 3(b) show the values measured on the day of cell production. Table I summarizes the cell performance. By comparing Figs. 3(a) and 3(b) (i.e., 0 day), the CuIbased PSCs were found to initially show a much lower efficiency than the spiro-based PSCs (ave. 9.16\% and max. 10.5\% for the spiro-based PSCs, and ave. 1.00\% and max. 2.22\% for the CuI-based PSCs.)

To determine whether the CuI-based PSCs have the aging effect, the photovoltaic performance was intermittently measured after cell production. All cells were stored in air under a dark condition, and humidity and temperature were kept at $\sim 40 \%$ and $\sim 30^{\circ} \mathrm{C}$, 
respectively. Figures 3(c) and 3(d) show $J$ - $V$ curves of the spiro-based PSC after 21 days of production and those of the CuI-based PSC after 20 days of production, respectively. The highest efficiency of the spiro-based PSC was 9.02\%, whereas that of the CuI-based PSC was $6.52 \%$, which was $~ 72 \%$ that of the spiro-based PSC, indicating that the CuI-based PSC had a positive aging effect. The $J$ - $V$ hystereses of the PSCs are also plotted in Fig. 3, where dotted and solid lines indicate forward and back scans, respectively. The $J$ - $V$ hysteresis of the CuI-based PSC was much smaller than that of the spiro-based PSCs. Sepalage et al. ${ }^{20)}$ have recently explained that the smaller hysteresis of the CuI-based PSC is attributed to the smaller local electric field generated in the perovskite/CuI system. With aging for 20 days, the hysteresis of the CuI-based PSC became slightly larger, but much smaller than that of the spiro-based PSC [Figs. 3(c)-(d)]. This smaller hysteresis is a merit to use the CuI HTL.

Figure 4 shows the aging effects (up to 40 days) of photovoltaic parameters (average values) of spiro- and CuI-based PSCs. For spiro-based PSCs, all parameters remained almost constant or decreased with aging. This is considered a crucial disadvantage of PSCs. On the other hand, for CuI-based PSCs, all parameters remained almost constant or slightly increased with aging. After $\sim 40$ day aging, the PCEs of spiro- and CuI-based PSCs were not quite different to each other. This is probably because the contact between the CuI HTL and the perovskite laye,r and that between the CuI HTL and the Au electrode improved with aging, resulting in an enhanced hole transportation, which is suggested by the FF improvement curve in Fig. 4(c).

To consider the performance results of CuI-based PSCs in Figs. 3 and 4, SEM observation was conducted. Figure 5 shows SEM images of (a) the starting CuI powder, (b) the surface of $\mathrm{CH}_{3} \mathrm{NH}_{3} \mathrm{PbI}_{3}$ layer, and (c) the surface of $\mathrm{CuI}$ layer on $\mathrm{CH}_{3} \mathrm{NH}_{3} \mathrm{PbI}_{3}$. The particle size of the starting CuI powder was $~ 10-50 \mu \mathrm{m}$ [Fig. 5(a)], and the CuI powder completely dissolved in the solvent (i.e., chlorobenzene, acetonitrile, and TBP). The particle size of the $\mathrm{CH}_{3} \mathrm{NH}_{3} \mathrm{PbI}_{3}$ active layer (without a CuI HTL/Au electrode) was $\sim 100-500 \mathrm{~nm}$ [Fig. 5(b)]. As shown in Fig. 5(c), the spin-coated CuI thin film covered the $\mathrm{CH}_{3} \mathrm{NH}_{3} \mathrm{PbI}_{3}$ active layer; however, some uncovered areas also existed. Actually, the CuI HTL in this study was difficult to visualize from cross-sectional SEM images (Fig. 6). Therefore, some $\mathrm{CH}_{3} \mathrm{NH}_{3} \mathrm{PbI}_{3}$ crystals may directly be in contact with the Au electrode, where the recombination between electrons (in the active layer) and holes (in the active layer and $\mathrm{Au}$ electrode) may occur.

Finally, different coating methods for CuI-based PSCs are listed in Table II. If we can optimize the coating conditions to suppress the direct contact, further improvement in PCE 
for CuI-based PSCs is expected.

\section{Conclusions}

In this study, we have prepared PSCs with a CuI HTL as a cost-effective hole conductor. The CuI-based PSC recorded $\eta=2.22 \%$ (max.) on the day of production and $\eta=6.52 \%$ (max.) after 20 days of production, whereas the spiro-based PSC (reference) recorded $\eta=10.5 \%$ (max.) on the day of production and $\eta=9.02 \%$ (max.) after 21 days of production. These results indicate that the CuI-based PSC had a positive aging effect. Moreover, the CuIbased PSC had a smaller hysteresis than the spiro-based PSC. Throughout this study, CuI is highly promising as a hole conductor for PSCs. We expect that the CuI-based PSC will be further improved by the optimization of coating processes.

\section{Acknowledgements}

We thank Prof. Kadowaki and Prof. Kashiwagi for the use of vacuum vapor deposition system, and Prof. Tamotsu Koyano (Cryogenics Division, Research Facility Center, University of Tsukuba) and Prof. Hiroya Abe (Osaka University) for their help in SEM observation.

\section{References}

1) A. Kojima, K. Teshima, Y. Shirai, and T. Miyasaka: J. Am. Chem. Soc. 131, 6050 (2009).

2) https://www.nrel.gov/pv/assets/images/efficiency-chart.png

3) J. Burschka, N. Pellet, S.-J. Moon, R. Humphry-Baker, P. Gao, M. K. Nazeeruddin, and M. Grätzel: Nature 499, 316 (2013).

4) T. Leijtens, B. Lauber, G. E. Eperon, S. D. Stranks, and H. J. Snaith: J. Phys. Chem. Lett. 5, 1096 (2014).

5) W. Ke, G. Fang, J. Wang, P. Qin, H. Tao, H. Lei, Q. Liu, X. Dai, and X. Zhao: ACS Appl. Mater. Interfaces 6, 15959 (2014).

6) S. Ryu, J. Seo, S. S. Shin, Y. C. Kim, N. J. Jeon, J. H. Noh, and S. I. Seok: J. Mater. Chem. A 3, 3271 (2015).

7) A. Abrusci, S. D. Stranks, P. Docampo, H.-L. Yip, A. K.-Y. Jen, and H. J. Snaith: Nano Lett. 13, 3124 (2013).

8) Z. Zhu, Y. Bai, H. K. H. Lee, C. Mu, T. Zhang, L. Zhang, J. Wang, H. Yan, S. K. So, 
and S. Yang: Adv. Funct. Mater. 24, 7357 (2014).

9) P. Qin, S. Tanaka, S. Ito, N. Tetreault, K. Manabe, H. Nishino, M. K. Nazeeruddin, and M. Grätzel: Nat. Commun. 5, 1 (2014).

10) S. Ye, W. Sun, Y. Li, W. Yan, H. Peng, Z. Bian, Z. Liu, and C. Huang: Nano Lett. 15, 3723 (2015).

11) S. Chavhan, O. Miguel, H.-J. Grande, V. Gonzalez-Pedro, R. S. Sánchez, E. M. Barea, I. Mora-Seró, and R. Tena-Zaera: J. Mater. Chem. A 2, 12754 (2014).

12) M. Jung, Y. C. Kim, N. J. Jeon, W. S. Yang, J. Seo, J. H. Noh, and S. I. Seok: ChemSusChem 9, 2592 (2016).

13) Z. Zhu, Y. Bai, T. Zhang, Z. Liu, X. Long, Z. Wei, Z. Wang, L. Zhang, J. Wang, F. Yan, and S. Yang: Angew. Chem., Int. Ed. 53, 12571 (2014).

14) Z. Liu, M. Zhang, X. Xu, L. Bu, W. Zhang, W. Li, Z. Zhao, M. Wang, Y.-B. Cheng, and H. He: Dalton Trans. 44, 3967 (2015).

15) S. Seo, I. J. Park, M. Kim, S. Lee, C. Bae, H. S. Jung, N. G. Park, J. Y. Kim, and H. Shin: Nanoscale 8, 11403 (2016).

16) C. Zuo and L. Ding: Small 11, 5528 (2015).

17) W. Yu, F. Li, H. Wang, E. Alarousu, Y. Chen, B. Lin, L. Wang, M. N. Hedhili, Y. Li, K. Wu, X. Wang, O. F. Mohammed, and T. Wu: Nanoscale 8, 6173 (2016).

18) B. A. Nejand, V. Ahmadi, S. Gharibzadeh, and H. R. Shahverdi: ChemSusChem 9, 302 (2016).

19) J. A. Christians, R. C. M. Fung, and P. V. Kamat: J. Am. Chem. Soc. 136, 758 (2014).

20) G. A. Sepalage, S. Meyer, A. Pascoe, A. D. Scully, F. Huang, U. Bach, Y.-B. Cheng, and L. Spiccia: Adv. Funct. Mater. 25, 5650 (2015).

21) M. Huangfu, Y. Shen, G. Zhu, K. Xu, M. Cao, F. Gu, and L. Wang: App. Surf. Sci. 357, 2234 (2015).

22) W. Sun, H. Peng, Y. Li, W. Yan, Z. Liu, Z. Bian, and C. Huang: J. Phys. Chem. C 118, 
16806 (2014).

23) F. Hao, C. C. Stoumpos, R. P. H. Chang, and M. G. Kanatzidis: J. Am. Chem. Soc. 136, 8094 (2014).

24) S. Inudo, M. Miyake, and T. Hirato: Phys. Status Solidi A 210, 2395 (2013).

25) D. Poplavskyy and J. Nelson: J. Appl. Phys. 93, 341 (2003).

26) L. Schmidt-Mende and M. Grätzel: Thin Solid Films 500, 296 (2006).

27) K. Tennakone, G. R. R. A. Kumara, I. R. M. Kottegoda, V. P. S. Perera, G. M. L. P. Aponsu, and K. G. U. Wijayantha: Sol. Energy Mater. Sol. Cells 55, 283 (1998).

28) M. N. Amalina, N. A. Rasheid, and M. Rusop: J. Nanomater. 2012, 637637 (2012).

29) M. I. Hossain, F. H. Alharbi, and N. Tabet: Sol. Energy 120, 370 (2015).

30) C. F. Cai, X.-Q. Meng, F.-M. Wu, and Y. Z. Fang: Chin. J. Lumin. 34, 721 (2013).

\section{Figure Captions}

Fig. 1. (Color online) (a) Conventional structure and (b) energy diagram of PSCs.

Fig. 2. (Color online) XRD patterns of (a) CuI powder/ thick film on the glass and (b) PSCs (HTM: spiro-OMeTAD or CuI).

Fig. 3. $J$ - $V$ curves of the prepared cells: (a) spiro based PSC (0 day), (b) CuI based PSC (0 day), (c) spiro based PSC (21 days) and (d) CuI based PSC (20 days). The $J$-V curves showing the highest performance are plotted in each figure. Inset values are for the highest performance: (a), (c), and (d) are for the back scan, and (b) is for the forward scan.

Fig. 4. (Color online) Aging effects of the photovoltaic parameters. ( $J_{\mathrm{sc}}, V_{\mathrm{oc}}, \eta$, and FF).

Fig. 5. SEM images of (a) starting CuI powder, (b) surface of $\mathrm{CH}_{3} \mathrm{NH}_{3} \mathrm{PbI}_{3}$ layer, and (c) surface of $\mathrm{CuI}$ layer on $\mathrm{CH}_{3} \mathrm{NH}_{3} \mathrm{PbI}_{3}$

Fig. 6. Cross-sectional SEM images: (a) spiro-based PSC $\left(\mathrm{TiO}_{2} \sim 200 \mathrm{~nm}\right.$ thickness / $\mathrm{CH}_{3} \mathrm{NH}_{3} \mathrm{PbI}_{3} \sim 450 \mathrm{~nm} /$ spiro-OMeTAD 150 nm) and

(b) CuI-based PSC $\left(\mathrm{TiO}_{2} \sim 500 \mathrm{~nm}\right.$ thickness $\left./ \mathrm{CH}_{3} \mathrm{NH}_{3} \mathrm{PbI}_{3}+\mathrm{CuI} 500 \mathrm{~nm}\right)$. 
Table I. Characteristics of prepared PSCs (measured on the same day of cell production).

\begin{tabular}{cccccc}
\hline HTM & & $J_{\mathrm{SC}}\left(\mathrm{mA} / \mathrm{cm}^{2}\right)$ & $V_{\mathrm{OC}}(\mathrm{V})$ & PCE $(\%)$ & FF \\
\hline \multirow{2}{*}{ spiro-OMeTAD } & Ave & $16.9 \pm 1.1$ & $0.83 \pm 0.02$ & $9.16 \pm 1.05$ & $0.66 \pm 0.03$ \\
& Max & 18.4 & 0.85 & 10.5 & 0.68 \\
\hline \multirow{2}{*}{ CuI $(0.1 \mathrm{M})$} & Ave & $11.0 \pm 2.15$ & $0.36 \pm 0.04$ & $1.00 \pm 0.46$ & $0.34 \pm 0.04$ \\
& Max & 14.7 & 0.42 & 2.22 & 0.40 \\
\hline
\end{tabular}

Table II. CuI based PSCs prepared by different coating methods.

\begin{tabular}{lccc}
\hline \multicolumn{1}{c}{ CuI coating methods } & CuI thickness & $\begin{array}{c}\text { Maximum } \\
\text { PCE (\%) }\end{array}$ & Ref. \\
\hline Automated dropcasting & $1.5-2.0 \mu \mathrm{m}$ & 6.0 & Christians et al. $^{19)}$ \\
Manual doctor blade & $\sim 400 \mathrm{~nm}$ & 7.5 & Sepalage et al. $^{20}$ \\
Spray coating & $17.5 \pm 1.5 \mu \mathrm{m}$ & 5.8 & Huangfu et al. $^{21)}$ \\
Spin coating + aging & $<100 \mathrm{~nm}^{\text {a) }}$ & 6.5 & This study \\
\hline
\end{tabular}

${ }^{a)}$ Mostly embedded between perovskite crystals 
(a)

$\mathrm{h}^{+}$

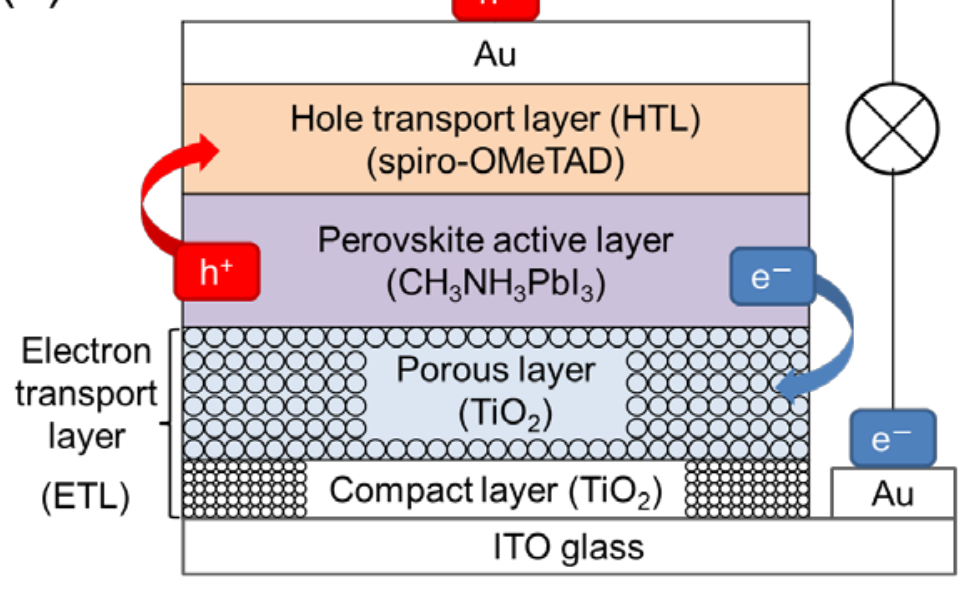

(b)

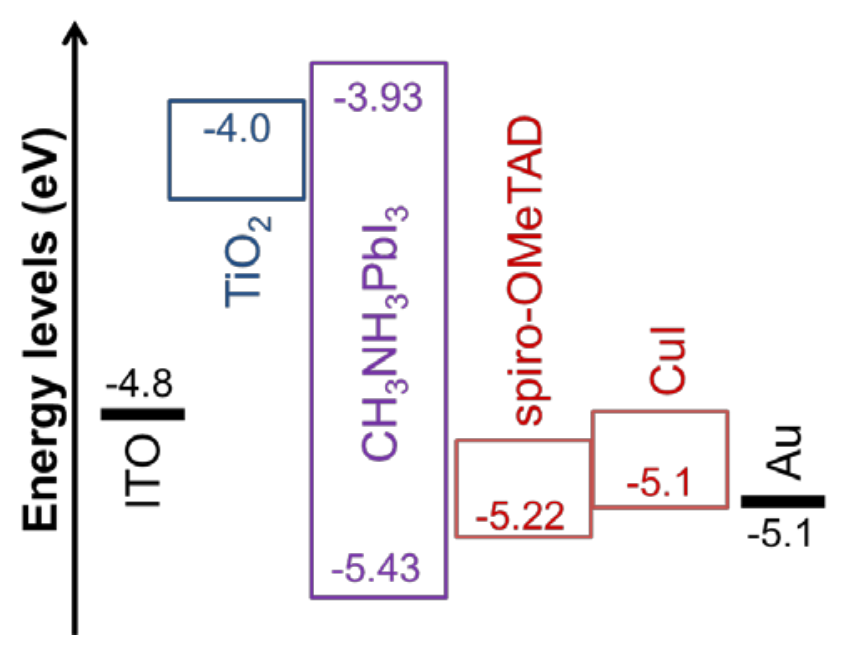

Fig. 1. (Color online) 
(a)
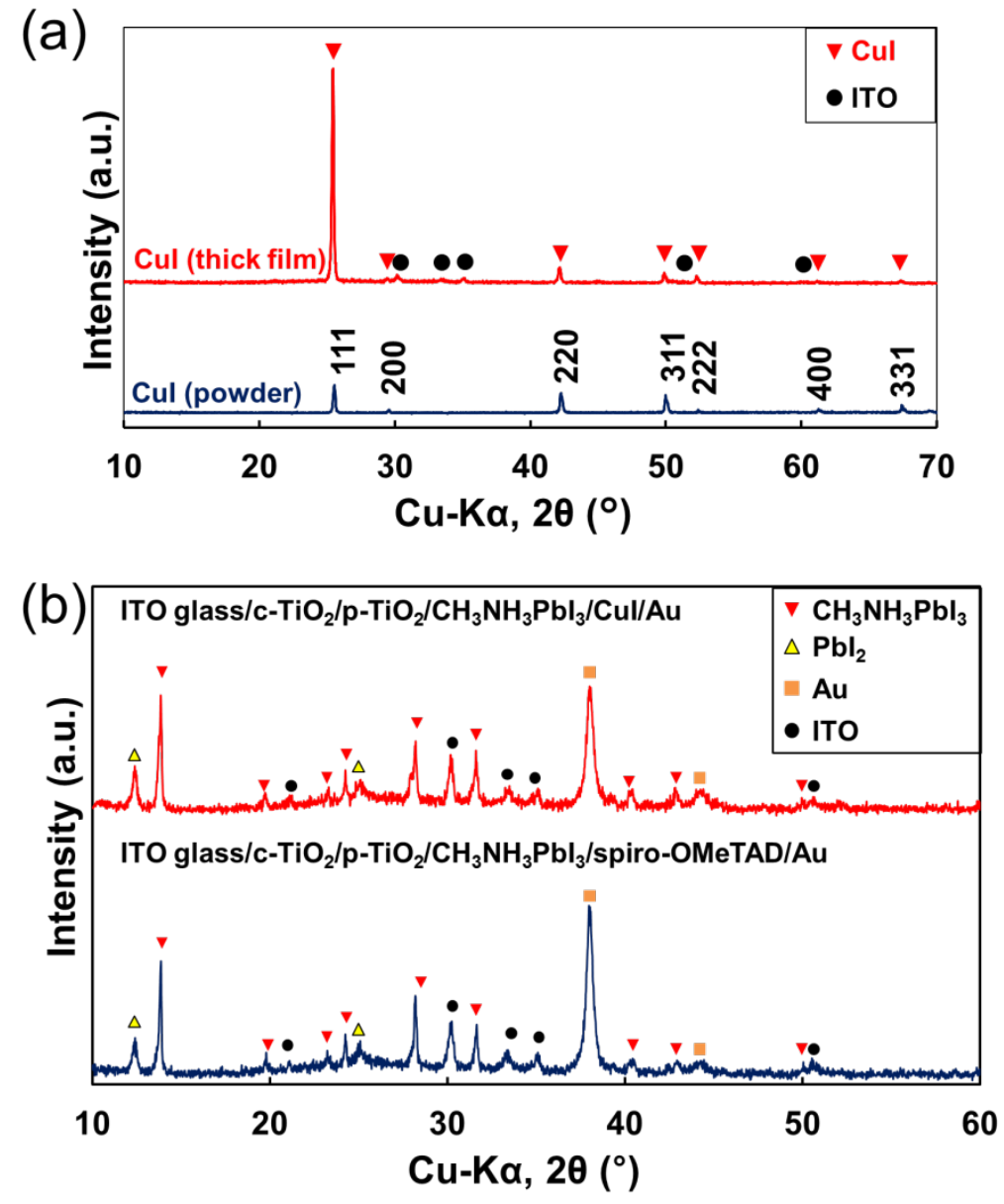

Fig. 2. (Color online) 
(a) spiro-OMeTAD

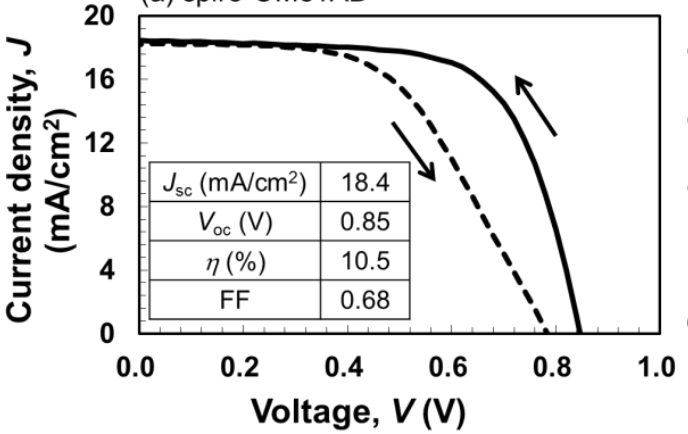

(c) spiro-OMeTAD, 21 days

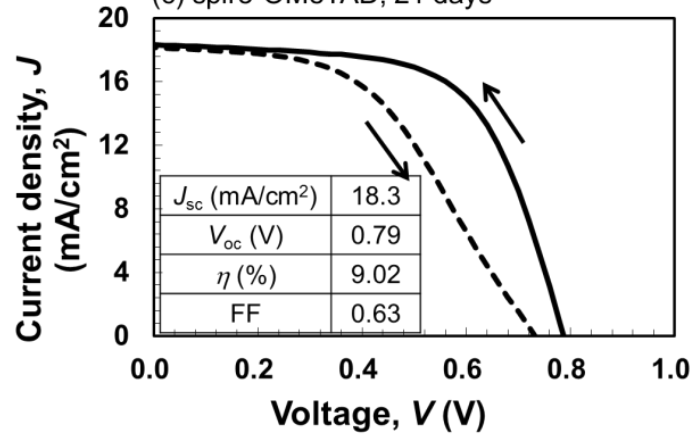

(b) Cul

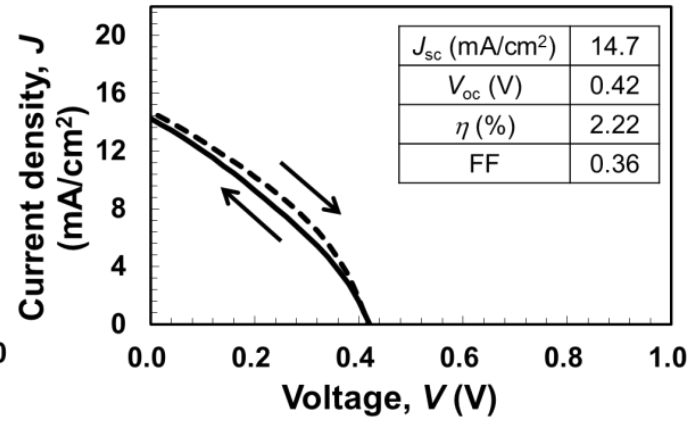

(d) Cul, 20 days

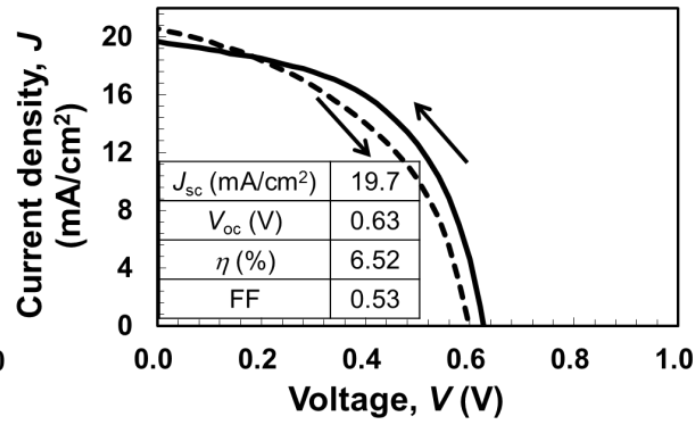

Fig. 3.
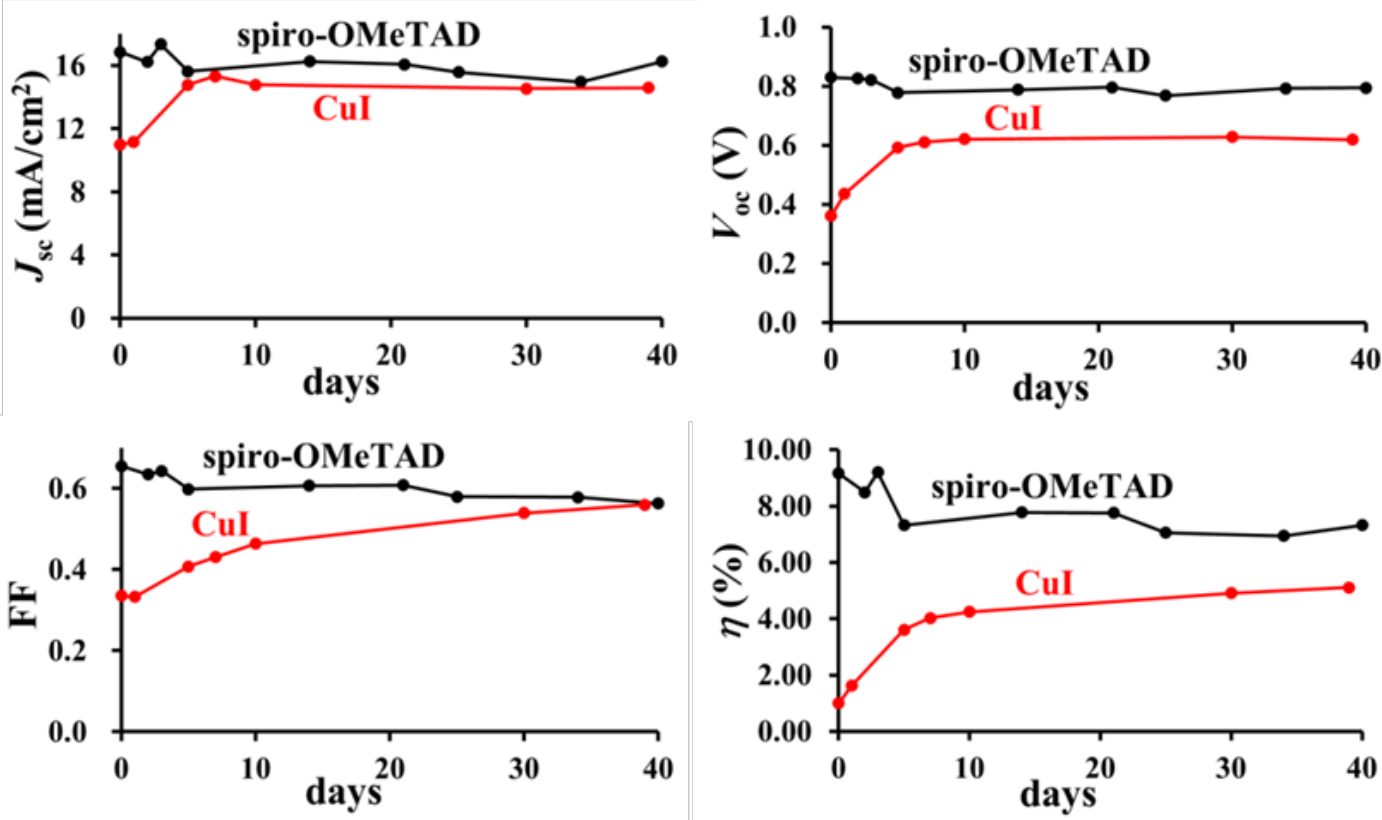

Fig. 4. (Color online) 

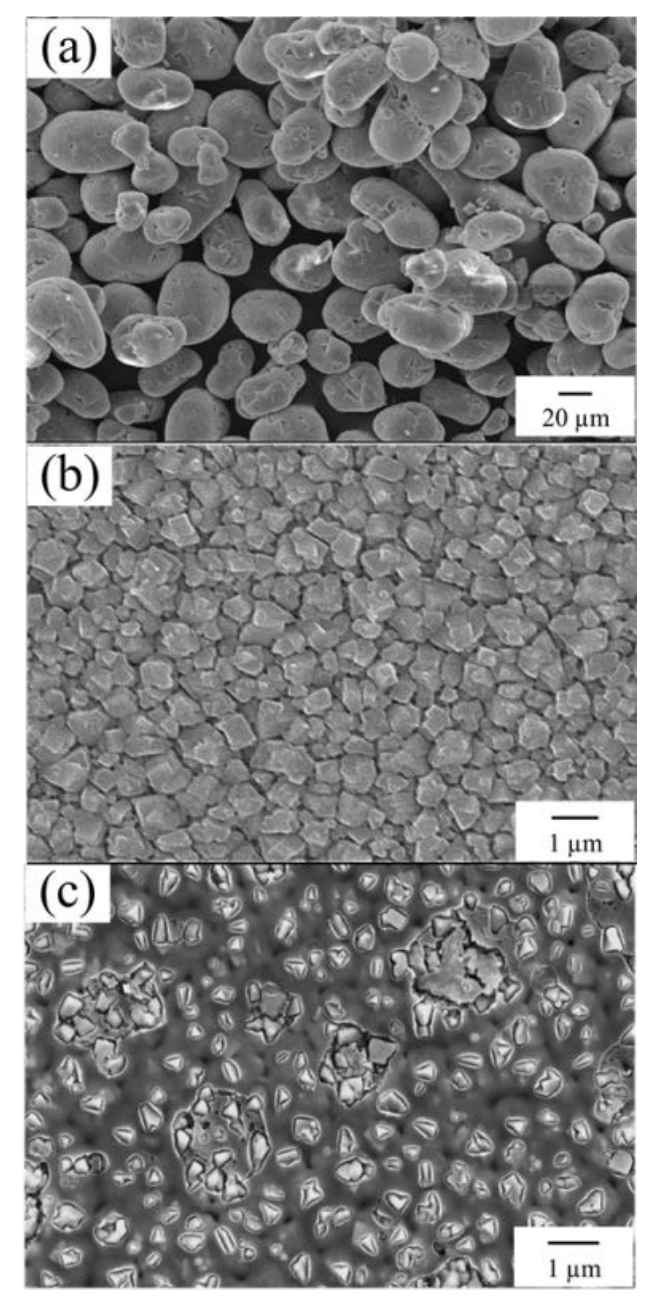

Fig. 5.

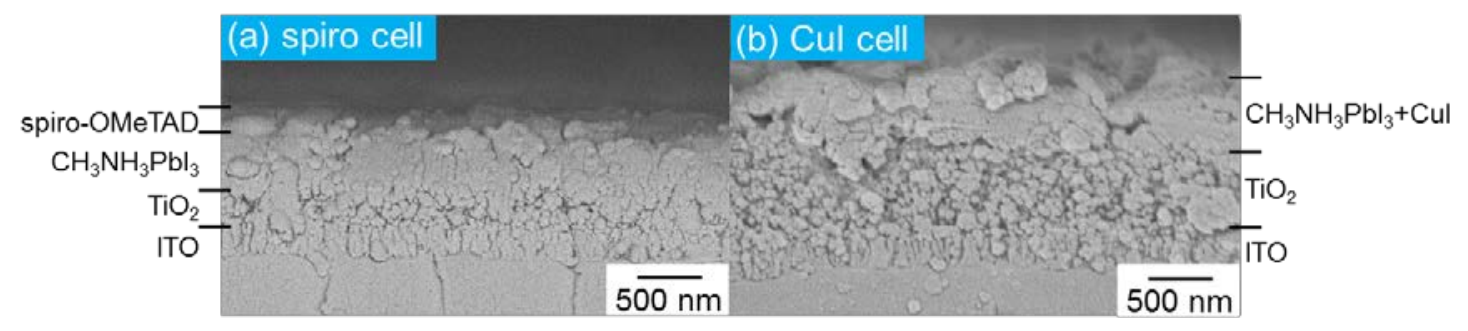

Fig. 6. (Color online) 